Metta, V. C. \& Mitchell, H. H. (1956). F. Nutr. 59, 50 I.

Miller, D. S. \& Bender, A. E. (1955). Brit. F. Nutr. 9, $3^{82 .}$

Mitchell, H. H. (1923-4). F. biol. Chem. 58, 873 .

Mitchell, H. H. (1924). Physiol. Rev. 4, 424.

Mitchell, H. H. (1944). Industr. Engng Chem. (Anal.), 16, 696.

Mitchell, H. H. \& Block, R. J. (1946). F. biol. Chem. 163, 599.

Mitchell, H. H., Burroughs, W. \& Beadles, J. R. (1936). F. Nutr. Ir, 257.

Mitchell, H. H. \& Carman, G. G. (1926). F. biol. Chem. 68, I83.

Mitchell, H. H., Hamilton, T. S. \& Beadles, J. R. (1945). F. Nutr. 29, 13.

Morgan, A. F. (1931). F. biol. Chem. 90, 77I.

Moulton, C. R. (1923). F. biol. Chem. 57, 79.

Murlin, J. R., Hayes, A. D. \& Johnson, K. (1953). F. Nutr. 5I, I 49.

Murlin, J. R., Szymanski, T. A. \& Nasset, E. C. (1948). F. Nutr. 36, I 7 I.

Murray, H. C. (1948). F. Nutr. 35, 257.

Osborne, T. B. \& Mendel, L. B. (1917). F. biol. Chem. 32, 369.

Osborne, T. B., Mendel, L. B. \& Ferry, E. L. (1919). F. biol. Chem. 37, 223.

Rubner, M. (1879). Z. Biol. 15, I 15.

Sauberlich, H. E. \& Salmon, W. D. (1955). F. biol. Chem. 214, 463.

Sumner, E. E. (1938). $\mathcal{~}$. Nutr. 16, 129.

Thomas, K. (1909). Arch. Anat. Physiol. Lpz. Physiol. Abt. p. 219.

Thomas, K. (19г I). Arch. Anat. Physiol. Lpz. Physiol. Abt. Suppl. p. 249.

\title{
Hyperphagia and gastric hypertrophy in rats adapted to intermittent starvation
}

\author{
BY EMA HOLEČKOVA \\ Laboratory for the Physiology and Pathophysiology of Metabolism, Czechoslovak \\ Academy of Sciences, Salmovská I, Prague 2, Czechoslovakia \\ AND P. FÁBRY \\ Institute of Human Nutrition, Prague I4, Czechoslovakia \\ (Received 23 Fune 1958-Revised 3 March 1959)
}

When laboratory rats were adapted to intermittent starvation by feeding them without restriction for fixed periods, alternating with gradually increased periods of starvation in which they were given only water, corresponding adaptive changes occurred in their food intake, in the morphology and physiology of the digestive tract and in the biochemical composition of their organs and tissues. The adaptive changes in the food intake and in the stomach are the subject of the present paper.

\section{EXPERIMENTAL}

Female albino rats from a random-bred colony of Wistar origin, of average weight from 100 to $200 \mathrm{~g}$ at the beginning of the experiments, were adapted to intermittent starvation in the manner previously described (Fábry, I955); periods of fasting alternated with single days when the animals had free access to a mixed diet containing $52.8 \%$ of the calories as carbohydrate, $25.5 \%$ as protein and $21.7 \%$ as fat. The periods of fasting for different experimental groups were gradually increased from $\mathrm{I}$ to 3 days during periods of 2 weeks as the minimum and of 6 weeks as the maximum. One group of eighteen rats was thus adapted and fed during 6 weeks, another group of 
twenty-four during 17 weeks and a third of eight during 6 weeks; the last group was re-fed for a subsequent 8 weeks with the usual stock diet. For each group of intermittently starved rats a similar group of the same number of controls fed to appetite was maintained throughout.

The quantities of food eaten during each whole week by the group of rats adapted for 17 weeks and by their control non-starved group were recorded. The amount of food eaten in a week divided by 7 represents the mean daily food intake of the nonstarved control group fed in seven daily portions. In the intermittently starved group, the mean quantity per day was calculated by dividing by 7 the total quantity of food eaten in four, three or two single portions in a week; the mean quantity of food eaten in one $\mathrm{r}$-day portion was calculated also.

At the end of the experiment both adapted and non-starved control rats were killed by decapitation $48 \mathrm{~h}$ after the last feed; the stomach was washed and weighed and the translucent and opaque parts were weighed separately. The material was prepared for histological examination in paraffin sections stained with haematoxylin and eosin.

In a further group of three animals fed every 2 nd day for 2 weeks, three times a week for 2 weeks and twice a week for 4 weeks, food containing Io $\%$ of contrast material was given to appetite in the evening of one day. X-ray photographs of the stomach of three adapted and of three non-starved control rats were taken next morning and again after $24 \mathrm{~h}$ fasting. The food intake of these two groups of rats had been measured previously every $2 \mathrm{~h}$ during $24 \mathrm{~h}$.

\section{RESULTS}

Intermittently starved rats grew more slowly than non-starved controls. When the group of twenty-four was fed every other day or three times a week, they still gained weight; feeding only twice a week for several weeks resulted in loss of weight, but the loss was not progressive, and, after a fall, the weight remained constant (Fig. I, upper curves).

The mean intake of food, expressed as $g$ food eaten per day, did not change in the non-starved control group. In the intermittently starved group, the mean intake of food expressed as consumption per day equalled the mean daily intake of the nonstarved group only in the $3^{\text {rd }}$ week of intermittent starvation, which was the period during which for 3 weeks the animals were fed every other day. Later, when the rats were fed only twice or three times a week, their mean intake of food per day remained low in comparison with the intake of the non-starved controls (Fig. I, lower curves), although the portion of food eaten by the intermittently starved rats, on the days on which they were fed, was much larger in the later weeks of intermittent starvation (Fig. 2). In the 17 th week of intermittent starvation, the non-starved rats ate on the average $133 \mathrm{~g}$ food in seven daily portions, but the intermittently starved animals ate an average of $\mathrm{I} I 2 \mathrm{~g}$ in only two $\mathrm{I}$-day portions.

The greatly increased consumption of food on the days of free access to it was demonstrated by X-ray pictures of rats fed every 2 nd day for 2 weeks, three times a week for 2 weeks and twice a week for 4 weeks, taken after unrestricted feeding during 
I night (P1. I). Each rat ate about $5^{6} \mathrm{~g}$ food during the night and the full stomach filled a great part of the abdomen. After $24 \mathrm{~h}$ fasting they still had more food in the stomach than fully fed rats consuming steadily about $20 \mathrm{~g}$ a day. The increase in food intake was most marked in the first $2 \mathrm{~h}$ after access to food, when the starved animals ate a mean amount of $\mathrm{I} \mathrm{I} \mathrm{g}$, whereas the non-starved ate only $2 \mathrm{~g}$ during an hour.

The increased quantity of food eaten in one portion caused changes in the weight and morphology of the stomach. The changes were studied after 6 weeks and 17 weeks of intermittent starvation and after 6 weeks of intermittent starvation followed by

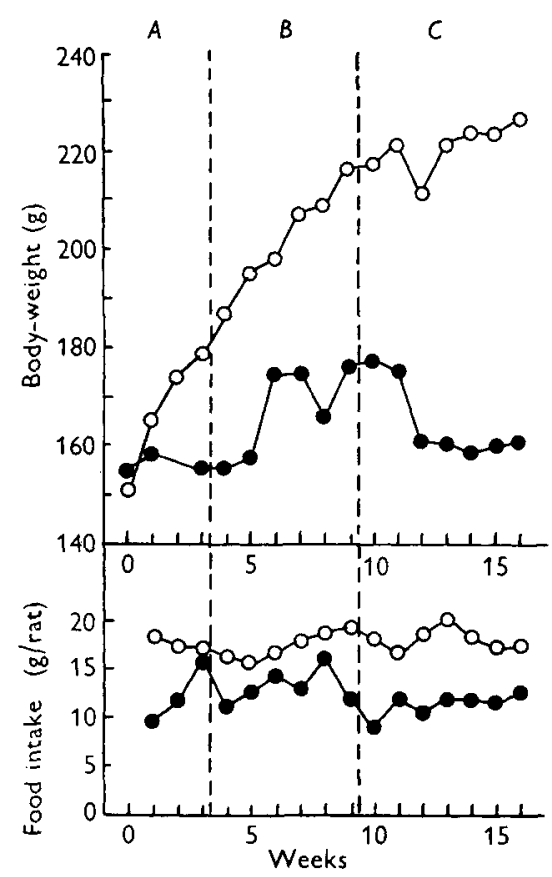

Fig. I

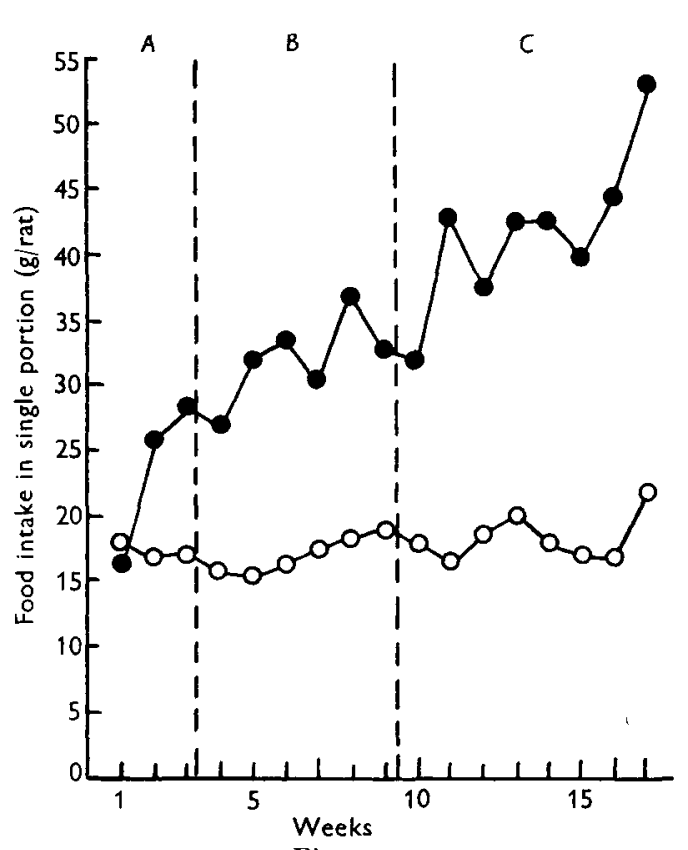

Fig. 2

Fig. 1. Mean body-weight (upper curves) and mean daily food intake (lower curves) of twenty-four female rats intermittently starved (- -$)$ and of twenty-four not starved $(0-0)$. The starved rats were fed every other day $(A)$, three times a week $(B)$ and twice a week $(C)$.

Fig. 2. Mean amount of food eaten in a single portion on $\mathrm{I}$ day by twenty-four female rats intermittently starved (-) and by twenty-four not starved $(0-0)$. The starved rats were fed every other day $(A)$, three times a week $(B)$ and twice a week $(C)$.

8 weeks of re-feeding. In Fig. 3 are shown the mean body-weight and the mean weight of the whole stomach and of the translucent and opaque parts separately in each of the three groups, expressed as percentages of the values for the non-starved rats. After 6 and 17 weeks of intermittent starvation the whole animal was about $25 \%$ lighter than the non-starved. In those re-fed the weight deficit was still $16 \%$. The stomach, on the contrary, got heavier; after 17 weeks of intermittent starvation, the increase was highly significant statistically. The increase was chiefly in the translucent part and was significant already after 6 weeks of intermittent starvation. In the opaque part it was significant only after 17 weeks. After re-feeding, the weight of the stomach 
Vol. I3

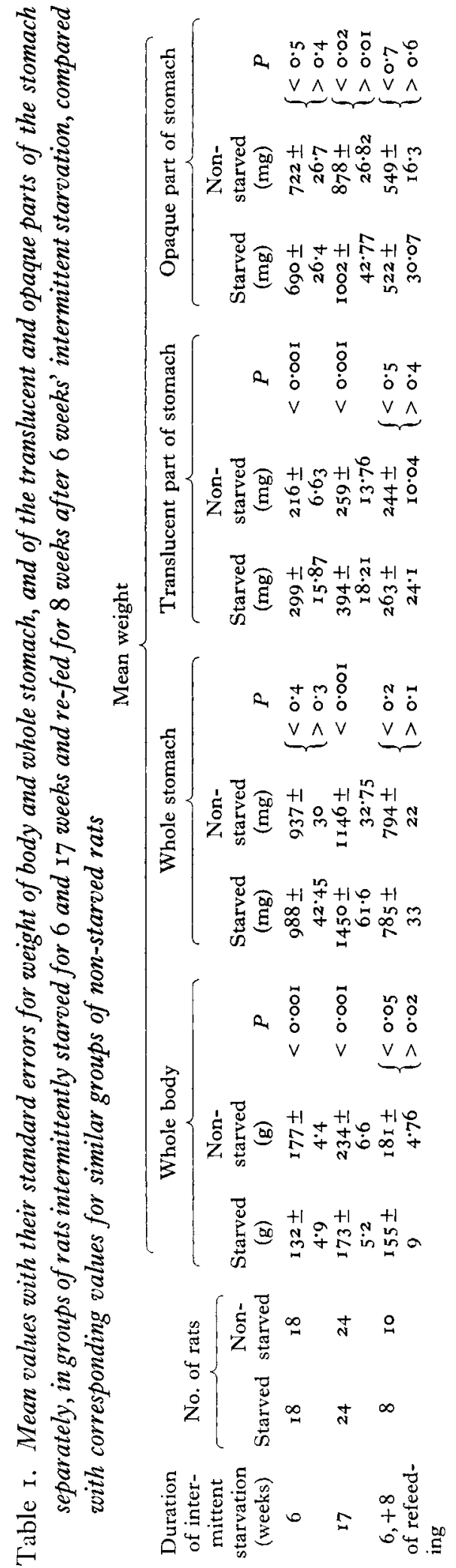


returned almost to normal, though the translucent part remained somewhat overweight. (See Table I for absolute values.)

Histological preparations showed marked hypertrophy of all parts of the stomach wall, most pronounced in the translucent part (Pl. 2). Pathological changes of the nature of hyperkeratosis, known to occur in undernutrition, were not seen.

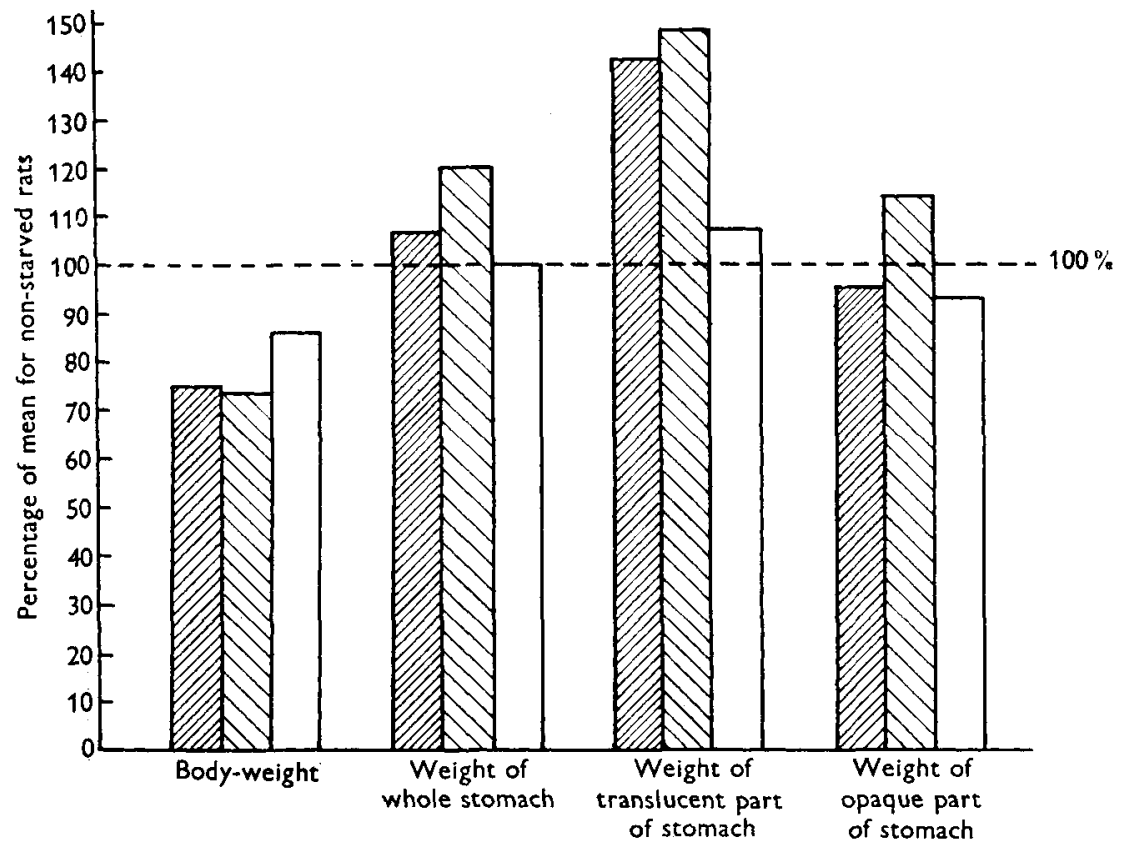

Fig. 3. Mean weight of the body and whole stomach, and of the translucent and opaque parts of the stomach separately, of eighteen rats intermittently starved for 6 weeks (囚), of twenty-four intermittently starved for 17 weeks $(\mathbb{\$})$ and of eight intermittently starved for 6 weeks and re-fed for 8 weeks $(\square)$. The values are expressed as percentages of the mean values for similar groups of nonstarved rats.

\section{DISCUSSION}

In the intermittently starved rats there are two main stimuli to be considered, change in the rhythm of food intake and change in the quantity of food eaten. Rats forced to endure deprivation of food for increasing periods 'learned' to overcome that situation by increasing their intake at the times when they had free access to food, and in that way they increased their reserves. The first reservoir of ingested food, the translucent part of the stomach, showed marked hypertrophy of the mucosa as well as of the muscles. In prolonged intermittent starvation, hypertrophy occurred even in the opaque part of the stomach. Fábry \& Kujalová (1958) found that the weight of the small intestine increased also in such rats, and the same authors (Kujalová \& Fábry, r $958 a, b)$ report an increase of glucose absorption and of alkaline-phosphatase activity in the same organ. The hypertrophy of the stomach and small intestine, combined with increased enzyme formation, occurred in conditions in which other organs of the animal and the body as a whole were losing a substantial part of their weight.

The effects of periodic excessive eating and of increased work for the digestive tract 
EMA HOLEČKOVÁ AND P. FÁBRY

Plate I

FEEDING AND GASTRIC HYPERTROPHY IN RATS

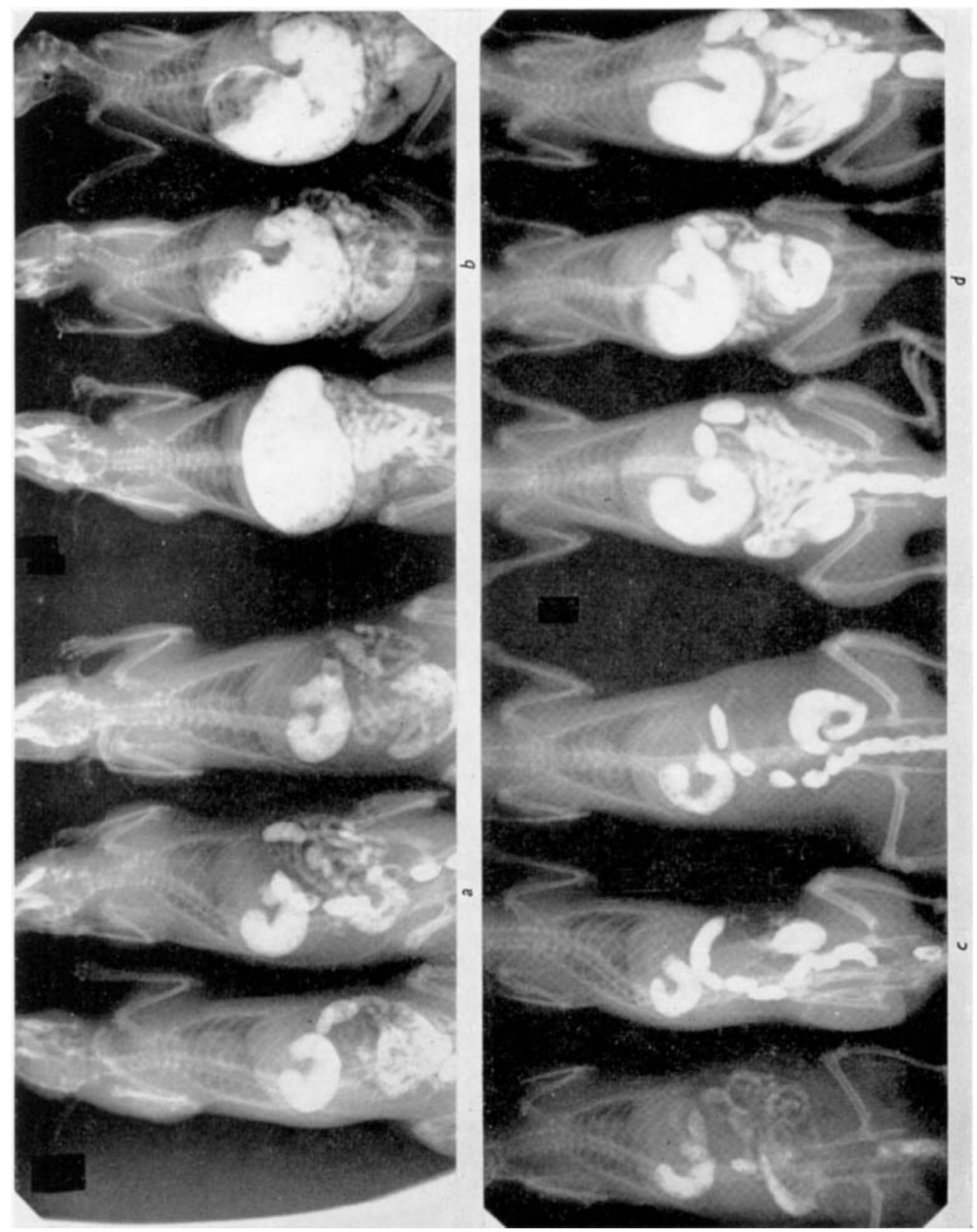

British Fournal of Nutrition, Vol. ${ }_{3} 3$, No. 3 
FEEDING AND GASTRIC HYPERTROPHY IN RATS
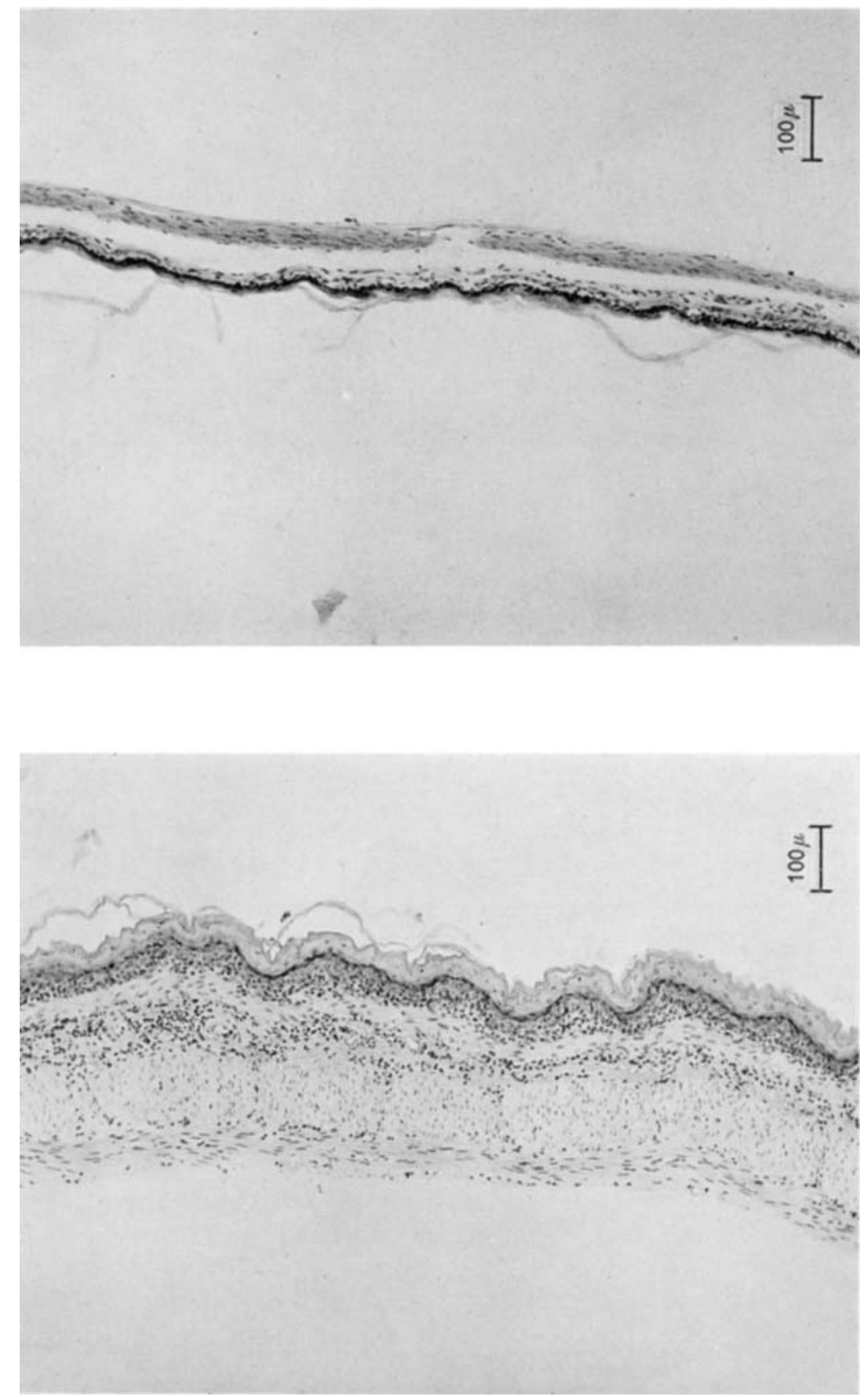

British Fournal of Nutrition, Vol. 13 , No. 3 
are reflected by changes in other organs and tissues. Fábry (1955) reported increased glycogenesis in the liver, and Hrưza \& Fábry (1955) drew attention to the relative increase in liver nitrogen. Gutmann \& Vrbová (1958) reported an increase in muscle glycogen, which depended on the persistence of normal innervation during fasting, and a relative increase in muscle protein. Some of these findings might be explained by the loss of fat due to the total caloric undernourishment, others by the great periodic increase of food ingested, which might play a part in the adaptive changes, by, for instance, increasing alkaline-phosphatase activity in the small intestine. The adaptation of rats subjected to intermittent starvation in the laboratory may be a reproduction of what occurs naturally in wild rats, which have to make the best possible use of any food found.

Besides the theoretical interest of the adaptive mechanism, some aspects suggest practical application of the observations. The hypertrophy of the intestine might serve as a model for the study of regenerative processes in that organ, and the hypertrophy of the stomach musculature, induced by changing the feeding habits, suggests that states in which the stomach has lost tone might be treated in that way.

\section{SUMMARY}

I. Two groups of adult female rats were adapted to intermittent starvation by gradually increased periods of fasting, alternating with days of free access to food during 6 and 17 weeks. A third group was adapted for 6 weeks and then re-fed for 8 weeks.

2. In the group adapted for 17 weeks the growth and the intake of food were recorded. With gradually increasing periods of fasting a gradually increasing intake occurred on the days of free access to food. In the last week of the experiment, the adapted animals ate on the average $112 \mathrm{~g}$ of food in two I-day portions, whereas non-starved rats ate on the average $133 \mathrm{~g}$ of food in seven daily portions.

3. The increased quantity of food eaten in one portion led to hypertrophy of the stomach mucosa and musculature, with a great increase in size. The change was most pronounced in the translucent part, but apparent also in the opaque part, after $I 7$ weeks of intermittent starvation. The hypertrophy was first apparent after 6 weeks of intermittent starvation; after re-feeding it gradually disappeared.

4. The hypertrophy of the stomach developed even although there was loss of weight by the whole body. Pathological changes in the gastric mucosa were not found.

\section{EXPLANATION OF PLATES}

Plate I

X-ray photographs of the stomach of rats.

(a) Three non-starved rats after feeding to appetite for $12 \mathrm{~h}$.

(b) Three rats fed to appetite for $\mathrm{I} 2 \mathrm{~h}$ after having been fed every and day for 2 weeks, three times a week for 2 weeks and twice a week for 4 weeks.

(c) Rats (a) after fasting for the next $24 \mathrm{~h}$.

(d) Rats $(b)$ after fasting for the next $24 \mathrm{~h}$.

Paraffin sections of the wall of the translucent part of the stomach from a non-starved rat (upper) and an intermittently starved rat (lower). Haematoxylin and eosin. 
REFERENCES

Fábry, P. (1955). Physiol. bohemoslov. 4, 33.

Fábry, P. \& Kujalová, V. (1958). Naturwissenschaften, 45, 373.

Gutmann, E. \& Vrbová, G. (1958). F. Physiol. r40, 50 P.

Hrůza, Z. \& Fábry, P. (1955). Physiol. bohemoslov. 4, I 52.

Kujalová, V. \& Fábry, P. (1958a). Physiol. bohemoslov. 7, 142.

Kujalová, V. \& Fábry, P. (1958b). Selected Papers of the Institute of Human Nutrition, Prague, 2, I 5 I.

\section{Malnutrition in African adults}

\section{4.* Intestinal absorption}

By E. G. HOLMES AND SYLVIA J. DARKE

East African Institute for Medical Research, Mwanza, Tanganyika

(Received 23 September 1958-Revised I6 December 1958)

The absorption of foodstuffs from the alimentary canal seems to have received rather less attention than it deserves. No firm estimate can be made of the nutritive value of a diet unless it is known what proportion of the nutrients which it contains is actually absorbed and utilized. This was recognized by F.A.O.: Committee on Calorie Conversion Factors and Food Composition Tables (1947) set up to consider the 'energy-yielding components of food and computation of calorie values'. In its report, the Committee discusses many of the difficulties and discrepancies caused by our lack of knowledge, both of the absorption of foods and often of their true energy and nitrogen values.

On account of the great importance of wheat flour as a staple food, its energy value, protein content and digestibility have been extensively studied. McCance, Widdowson, Moran, Pringle \& Macrae (1945) and McCance \& Walsham (1948-9) who have made detailed investigations have referred to the earlier literature on the subject. We have found comparatively few data dealing with other foodstuffs or with mixed diets, which, rather than a single foodstuff, are normally consumed even by primitive or economically backward peoples.

We suggest that it is usually of greater practical importance to study the absorption of a mixed diet than of an individual foodstuff. It is well known that absorption, particularly of nitrogen, is adversely affected by the presence of fibre in the diet. It may be that the fibre causes an increase in faecal $\mathrm{N}$ derived chiefly not from the food consumed, but from the intestinal epithelium: it will nevertheless diminish the $\mathrm{N}$ available to the body. The fact that the nutrients of an individual foodstuff may be completely absorbed is only of academic interest if, from the diet of which it forms a part, considerable quantities of energy and $\mathrm{N}$ are lost in the stool.

$$
\text { * Paper no. 3: Brit. F. Nutr. (1956), ro, } 198 \text {. }
$$

